\title{
BMJ Open Hormone replacement therapy and cancer survival: a longitudinal cohort study: protocol paper
}

\author{
Tom Alan Ranger (D , ${ }^{1}$ Judith Burchardt, ${ }^{1}$ Ashley Kieran Clift (D) , \\ Winnie Xue Mei (D) , ${ }^{1}$ Carol Coupland, ${ }^{2}$ Pui San Tan, ${ }^{1}$ Sharon Dixon (D) , 1 \\ Christopher Robert Cardwell, ${ }^{3}$ Julia Hippisley-Cox (i) ${ }^{1}$
}

To cite: Ranger TA, Burchardt J, Clift AK, et al. Hormone replacement therapy and cancer survival: a longitudinal cohort study: protocol paper. BMJ Open 2021;11:e046701. doi:10.1136/ bmjopen-2020-046701

- Prepublication history for this paper is available online. To view these files, please visit the journal online (http://dx.doi org/10.1136/bmjopen-2020046701).

Received 06 November 2020 Accepted 30 June 2021

Check for updates

(C) Author(s) (or their employer(s)) 2021. Re-use permitted under CC BY. Published by BMJ.

${ }^{1}$ Nuffield Department of Primary Care Health Sciences, University of Oxford, Oxford, UK

${ }^{2}$ Division of Primary Care, University of Nottingham, Nottingham, UK

${ }^{3}$ School of Medicine, Dentistry and Biomedical Sciences, Queen's University Belfast Belfast, UK

Correspondence to

Dr Tom Alan Ranger;

tom.ranger@phc.ox.ac.uk

\section{ABSTRACT}

Introduction Hormone replacement therapy (HRT) can help women experiencing menopausal symptoms, but usage has declined due to uncertainty around risks of cancer and some cardiovascular diseases (CVD). Moreover, improved cancer survival rates mean that more women who survive cancer go on to experience menopausal symptoms. Understanding these relationships is important so that women and their clinicians can make informed decisions around the risks and benefits of HRT. This study's primary aim is to determine the association between HRT use after cancer diagnosis and the risk of cancer-specific mortality. The secondary aims are to investigate the risks of HRT on subsequent cancer, all-cause mortality and CVD.

Methods and analysis We will conduct a population-based longitudinal cohort study of 18-79year-old women diagnosed with cancer between 1998 and 2020, using the QResearch database. The main exposure is HRT use, categorised based on compound, dose and route of administration, and modelled as a time-varying covariate. Analysis of HRT use precancer and postcancer diagnosis will be conducted separately. The primary outcome is cancer-specific mortality, which will be stratified by cancer site. Secondary outcomes include subsequent cancer diagnosis, CVD (including venous thromboembolism) and all-cause mortality. Adjustment will be made for key confounders such as age, body mass index, ethnicity, deprivation index, comorbidities, and cancer grade, stage and treatment. Statistical analysis will include descriptive statistics and Cox proportional hazards models to calculate HRs and $95 \%$ Cls.

Ethics and dissemination Ethical approval for this project was obtained from the QResearch Scientific Committee (Ref: OX24, project title 'Use of hormone replacement therapy and survival from cancer'). This project has been, and will continue to be, supported by patient and public involvement panels. We intend to the submit the findings for peer-reviewed publication in an academic journal and disseminate them to the public through Cancer Research UK.

\section{BACKGROUND}

\section{Prevalence of HRT use}

Hormone replacement therapy (HRT) involves clinical provision of the female sex hormone oestrogen either on its own or in combination with another hormone,
Strengths and limitations of this study

- This is an open cohort study comprising a nationally representative sample of English women.

- The cohort consists of General Practice (GP) clinic data linked to hospital records, the English national cancer registry and English national death registry.

- This study has access to detailed information on hormone replacement therapy prescriptions, allowing analysis with consideration of the specific compound, dose, route of administration and duration of exposure.

- This study is limited by high rates of missing data for cancer grade and stage, although completeness has improved in recent years, this will be accounted for using appropriate multiple imputation techniques.

progestogen. It is an effective and important treatment for symptoms of the menopause, including vasomotor symptoms (hot flushes and night sweats), urogenital atrophy ${ }^{1}$ and postmenopausal osteoporosis. ${ }^{2}$ Yet between 2002 and 2005, HRT usage in the UK dropped from approximately $29 \%$ of postmenopausal women to approximately $11 \%,{ }^{3}$ and this pattern was consistent across Europe. ${ }^{4}$ The drop in usage has been attributed to the widely reported findings of the Million Women's Study ${ }^{5}$ and the early cessation of the Women's Health Initiative trial, ${ }^{346}$ which concluded that an observed increase in risk of cardiovascular events and breast cancer in women taking combined oestrogen and progestogen HRT outweighed the benefits of reduced rates of colorectal cancer and osteoporotic fractures. ${ }^{7}$ Evidence from a recent Cochrane systematic review and metaanalysis though, suggests that HRT remains an important treatment option for women with severe menopausal symptoms who do not have other risk factors, such as oestrogen sensitive cancers. ${ }^{8}$ Given the demonstrated risks and benefits of HRT, there is a need to 
clarify which women can use it safely, to treat menopausal symptoms without unduly increasing their risk of adverse outcomes.

\section{HRT in women with cancer}

The role of oestrogen in cancer is complex, with evidence that it accelerates cancer progression in some sites but slows it in others. For instance, preclinical studies have shown that oestrogen stimulates growth in bladder ${ }^{9}$ and gastric cancer cell lines ${ }^{10}$ but, in contrast, similar studies found that it inhibits cell growth and/or induces apoptosis in oesophageal adenocarcinoma ${ }^{11}$ and malignant melanoma cell lines. ${ }^{12}$ What's more, in a mouse model oestrogen increased the number and volume of lung adenocarcinomas, ${ }^{13}$ and molecular pathological studies have shown oestrogen receptor expression is associated with metastasis and poorer survival in gastric cancer. ${ }^{14}$ Epidemiological studies also report contrasting findings depending the cancer of interest, with some showing markedly lower incidence and slightly better survival for women compared with men for many cancers, ${ }^{15} 16$ whereas another study demonstrated survival after gastric cancer is worse in young women ( $<45$ years old) than in young men, but similar in older women and men. ${ }^{17}$ The complex relationship between oestrogen and cancer raises questions as to how HRT can be safely provided for women experiencing menopausal symptoms.

Similar to investigations of oestrogen's role in various cancers, findings from studies of HRT and cancer risk are mixed. For example, HRT use is associated with a reduced risk of liver, ${ }^{18-20}$ oesophageal ${ }^{20}$ and colorectal cancers ${ }^{20-23}$ but an increased risk of glioma and meningioma with use of oestrogen only HRT. ${ }^{24}$ In some cases evidence is conflicting for individual cancers, for example, a recent meta-analysis of lung cancer found a reduced risk in women taking $\mathrm{HRT}^{25}$ but an earlier meta-analysis found no effect; ${ }^{26}$ and in non-Hodgkin's lymphoma, for which a pooled analysis of case-control studies showed decreased incidence in women using HRT, ${ }^{27}$ but two cohort studies found no effect. ${ }^{28}{ }^{29}$ Furthermore, a cohort study found bladder cancer to be less common in women using combined, but not oestrogen-only HRT, ${ }^{30}$ suggesting that the specific HRT prescription affects its association with cancer.

There are also important questions relating to the risk of HRT use by women who have survived or are living with cancer. This is increasingly important for several reasons: first, improved survival rates from cancer mean female survivors are increasingly likely to experience menopause $;{ }^{31}$ second, in young women with cancer, the associated treatment may cause primary ovarian insufficiency, ${ }^{31} 32$ inducing menopause and thus potentially indicating HRT in this demographic; and third, the induction of 'surgical' menopause by hysterectomy and oophorectomy could be an indication for HRT. ${ }^{33}$ While a number of studies have found protective effects of HRT after colorectal cancer, ${ }^{34-36}$ epidemiological evidence at other cancer sites is sparse. For instance, HRT use after cancer diagnosis was associated with reduced mortality in 205 patients with melanoma, ${ }^{37}$ but this was based on only one cancer-specific death in HRT users. Similarly, HRT before diagnosis was associated with reduced mortality in 234 patients with primary liver cancer, but HRT after diagnosis was not investigated. ${ }^{19}$ A case control study of patients with Hodgkin's lymphoma with and without subsequent breast cancer did not find that risk was increased by HRT. ${ }^{38}$ Finally, in a study of 130 patients with leukaemia no excess recurrences were observed in HRT users. ${ }^{39}$ Further investigation into the potential association between HRT and cancer survival is warranted because existing evidence comes from small studies with limited power, many of which did not investigate HRT after diagnosis, and many cancer sites have not been investigated at all.

Despite the lack of high quality epidemiological evidence, there have been suggestions that HRT should be used cautiously, or not at all, in patients with lung, ${ }^{3140}$ bladder, ${ }^{3141}$ gastric ${ }^{3141}$ and brain cancer. ${ }^{3141}$ These recommendations may be concerning for patients, and for clinicians there is limited information on providing HRT in women with cancers other than breast cancer in clinical guidelines. ${ }^{42} 43$ This can lead to avoidance of HRT in line with the 'precautionary principle', but such an approach has been severely criticised because of the clear benefits of HRT in reducing menopausal symptoms and increasing health-related quality of life. ${ }^{314}$ There is a need to clarify the relationship between HRT and non-oestrogen dependent cancers so that women of all ages who survive cancer can make informed choices with their treating clinicians as to the risks and benefits of HRT.

\section{Risk of cardiovascular disease and venous thromboembolism associated with HRT}

In addition to cancer, there are concerns that HRT may lead to cardiovascular complications. A recent Cochrane systematic review with meta-analysis of 22 largely high quality studies found moderate evidence that combined, continuous HRT is associated with an increased risk of myocardial infarction (MI), stroke and venous thromboembolism (VTE), and that oestrogen only, continuous HRT is associated with stroke and VTE but not MI. ${ }^{8}$ The authors concluded that while the absolute risk of these outcomes remained low, the clear association meant that the increased relative risk is a relevant consideration for all women and may contraindicate HRT in those at increased risk of cardiovascular disease (CVD). A more recent systematic review of 33 observational studies, however, had contradictory findings that HRT may protect against CVD, and that the duration, dose, timing and means of HRT administration affected the relationship. ${ }^{45}$ Importantly, the authors noted inconsistent results in the included studies and a wide range in their overall scientific quality. The higher quality of studies included in the Cochrane review lend greater weight to its findings, but the more recent systematic review indicates that 
further research into the specific type and administration of HRT in high quality studies is needed.

\section{Summary}

There are legitimate concerns about the safety of prescribing HRT for women with cancer and those at elevated risk of VTE or CVD. The role of HRT in improving the quality of life for women during menopause, however, means that understanding how and for whom it can be safely prescribed is essential. Furthermore, the increasing number of women who survive cancer and go on to experience menopausal symptoms suggests that investigation is warranted into this demographic specifically.

\section{Aims and objectives}

Our primary aim is to determine the association between HRT use and the risk of cancer-specific mortality in women with a range of common cancers. Our secondary aim is to quantify the risks of HRT associated with subsequent cancer, all-cause mortality, CVD and VTE in women with cancer. Our study will provide patients with cancer and clinicians with the high quality evidence of the safety of HRT in patients with cancer, allowing them to make informed decisions, and will provide important mechanistic insights into the role of oestrogen in cancer progression.

\section{METHODS AND ANALYSIS \\ Study design and data source}

A population-based cohort study will be conducted using the QResearch linked database. QResearch is a large, validated database of anonymised electronic health records and is representative of the English general population. ${ }^{46}$ It compiles patient data at an individual level from GP practices through the Egton Medical Information Systems electronic health records and has linkages to National Health Service (NHS) data through the NHS Digital Hospital Episode Statistics (HES) platform, the English national cancer registry and the English national death register, and has been described in detail previously. ${ }^{47}$

\section{Study sample}

We will identify an open cohort of women aged 18-79 years who have been registered at a GP clinic contributing data to QResearch for at least 1 year prior to diagnosis

Table 1 Included cancer sites of primary tumours by classification

\begin{tabular}{|c|c|}
\hline Category & Specific tumour site \\
\hline Haematological & $\begin{array}{l}\text { Leukaemia, multiple myeloma, non- } \\
\text { Hodgkin's lymphoma }\end{array}$ \\
\hline Gastrointestinal & $\begin{array}{l}\text { Oral, oesophageal, gastric, liver, } \\
\text { pancreatic, colorectal }\end{array}$ \\
\hline Gynaecological & Cervical, ovarian, endometrial \\
\hline Urogenital & Renal, bladder \\
\hline Other cancer sites & $\begin{array}{l}\text { Malignant melanoma, lung, thyroid, } \\
\text { brain }\end{array}$ \\
\hline
\end{tabular}

of one of the included types of cancer (table 1). Women with cancer will be identified from the English national cancer registry and this will be supplemented with GP clinic records and HES data. The study period is between 1998 and the most recent available data, with censoring at either the date of death or the end of the study period in the primary analysis, and at development of subsequent cancer, CVD or VTE in the relevant secondary analyses. Exclusion criteria are: women with a previous diagnosis of invasive cancer (other than those listed) or who have less than 1 year of follow-up available in the database. Breast cancer will not be included since HRT is contraindicated in breast cancer and oestrogen dependent tumours. ${ }^{242} 48$

\section{Exposure}

We will extract data on HRT prescriptions from the QResearch database. Treatment will be categorised based on compound (type of oestrogen and type of progestogen where applicable), route of administration (oral, transdermal, vaginal, injection or implant), dose ( $\leq 0.625 \mathrm{mg}$ for oral conjugated equine oestrogen, $\leq 1 \mathrm{mg}$ for oral estradiol, $\leq 50 \mu \mathrm{g}$ for transdermal estradiol, ${ }^{49}$ timing (ie, relative to cancer diagnosis) and duration. Daily defined doses (DDDs) will be extrapolated from prescription information where possible; however, it may not be possible in some cases, such as administration by transdermal patch or gel.

\section{Outcomes}

\section{Outcomes related to cancer mortality}

The primary outcome is cancer specific mortality where cancer is recorded as the primary or underlying cause of death. This will be ascertained using the primary or underlying cause of death as recorded on the linked mortality data from the Office of National Statistics death register. Our secondary outcomes will be incident cases of cancer as recorded on either the GP, hospital, cancer registry or linked mortality record and all-cause mortality.

\section{Outcomes related to CVD and VTE}

A CVD event will be defined as the earliest record of CVD where it is the primary reason for admission on the GP or HES databases, or where it is recorded as primary cause of death on the mortality record. A CVD event will include coronary heart disease or stroke.

As for CVD, a VTE event will be defined as the earliest record of VTE on any of the three linked data sources (GP, HES or mortality record). VTE will include deep vein thrombosis or pulmonary embolism.

\section{Confounding variables}

Key demographic factors, potentially confounding factors and data relating to the secondary outcome (CVD) are listed below and will be obtained from GP records. Categories of confounders that may apply to both outcomes but with different specific inclusions (eg, pharmacotherapy) are listed in table 2, with specific inclusions shown separately for each outcome. 
Table 2 Categories of confounders with specific inclusions for each outcome shown separately

\begin{tabular}{|c|c|c|}
\hline & Cancer-related analyses & CVD and VTE-related analyses \\
\hline $\begin{array}{l}\text { Charlson Comorbidity Index } \\
\text { (CCl) conditions }\end{array}$ & $\begin{array}{l}\text { Cardiovascular diseases } \\
\text { Coronary heart disease (myocardial } \\
\text { infarction or angina) } \\
\text { Congestive cardiac failure } \\
\text { Peripheral vascular disease } \\
\text { Stroke/ transient ischaemic attack } \\
\text { Gastrointestinal conditions } \\
\text { Peptic ulcer disease } \\
\text { Liver disease } \\
\text { Other CCl conditions } \\
\text { Othereatory bowel disease } \\
\text { Dementia } \\
\text { Chronic obstructive pulmonary } \\
\text { disease } \\
\text { Connective tissue disease } \\
\text { Haemiplegia } \\
\text { Moderate or severe chronic kidney } \\
\text { disease } \\
\text { Diabetes mellitus (type } 1 \text { or type 2) } \\
\text { HIV/ AIDS }\end{array}$ & $\begin{array}{l}\text { Gastrointestinal conditions } \\
\text { Peptic ulcer disease } \\
\text { Liver disease } \\
\text { Other CCI conditions } \\
\text { Dementia } \\
\text { Chronic obstructive pulmonary disease } \\
\text { Connective tissue disease } \\
\text { Hemiplegia } \\
\text { Moderate or severe chronic kidney disease } \\
\text { Diabetes mellitus (type } 1 \text { or type } 2 \text { ) } \\
\text { HIV/ AIDS }\end{array}$ \\
\hline Other comorbidities & $\begin{array}{l}\text { Severe mental illness } \\
\text { Depression } \\
\text { Venous thromboembolism } \\
\text { Vertebrobasilar insufficiency } \\
\text { syndrome } \\
\text { Anaemia }\end{array}$ & $\begin{array}{l}\text { Severe mental illness } \\
\text { Depression } \\
\text { Anaemia }\end{array}$ \\
\hline $\begin{array}{l}\text { Pharmacotherapy (other than } \\
\text { HRT and chemotherapy) }\end{array}$ & $\begin{array}{l}\text { Aspirin } \\
\text { Statins } \\
\text { Losartan } \\
\text { Metformin }\end{array}$ & $\begin{array}{l}\text { Anticoagulant drugs-warfarin, oral and parenteral } \\
\text { anticoagulants } \\
\text { Antihypertensive drugs-Angiotensin Converting Enzyme } \\
\text { (ACE)-inhibitors, beta-blockers, calcium channel blockers, } \\
\text { diuretics } \\
\text { Antiplatelet drugs - aspirin, clopidogrel, dipyridamole, } \\
\text { prasugrel, ticagrelor, ticlopidine } \\
\text { Mental health drugs } \\
\text { - Antidepressants - tricyclic antidepressants, compound } \\
\text { - antidepressants, mono-amine oxidase inhibitors } \\
\text { - Antipsychotic drugs } \\
\text { - Non-steroidal anti-inflammatories } \\
\text { - Opioids } \\
\text { Drugs of cancer treatment-tamoxifen, aromatase inhibitors, } \\
\text { thalidomide, lenalidomide, bevacizumab } \\
\text { Immunosuppressant drugs } \\
\text { Antidiabetes drugs-insulin, oral hypoglycaemics } \\
\text { Prostaglandin analogues } \\
\text { Other hormone therapies } \\
\text { - Oral contraceptive drugs-dianette } \\
\text { - Topical hormone drugs } \\
\text { - Megestrol acetate }\end{array}$ \\
\hline
\end{tabular}

CVD, cardiovascular disease; HRT, hormone replacement therapy; VTE, venous thromboembolism.

\section{Demographic and lifestyle factors}

- Year of birth.

- Age at cancer diagnosis.

- Townsend deprivation score.

- Most recent body mass index (BMI) prior to outcome diagnosis.

- Family history of cancer.

- Ethnicity (White, Indian, Bangladeshi, Pakistani, Chinese, other Asian, Caribbean, Black African, other).

- Most recent smoking status (never, former, light, moderate, heavy) prior to outcome diagnosis.
- Most recent alcohol consumption status (non-drinker, trivial, light, moderate, heavy, very heavy) prior to outcome diagnosis.

- Geographical region (East of England, East Midlands, West Midlands, London, North East, North West, South Central, South East, South West, Yorkshire and the Humber). ${ }^{50}$

\section{Tumour-specific factors}

Histology

- Stage: 1-4 as per Tumour Nodes Metastases classification, or International Federation of Gynaecology and 
Obstetrics (FIGO) staging system for gynaecological cancers.

- Grade: well, moderately, poorly or not differentiated. Cancer treatment within 6 months of diagnosis ${ }^{51}$

- Radiotherapy.

- Chemotherapy.

- Hormonal therapy for cancer as recorded on the cancer registry.

- Cancer-related surgery:

- Lung - resection, for example, pneumonectomy or lobectomy.

- Colorectal-haemicolectomy, colectomy, endoscopic resection.

- Pancreatic-pancreaticoduodenectomy, distal pancreatectomy.

- Gynaecological-hysterectomy with or without bilateral salpingo-oophorectomy, pelvic exenterations, cone biopsy or Large Loop Excistion of the Transformation Zone (LLETZ).

- Gastro-oesophageal-oesophagectomy, gastrectomy.

- Oral-lip resection, excision of oral lesion, glossectomy, maxillectomy, mandibulectomy, laryngectomy.

- Thyroid cancers-thyroidectomy with or without neck dissection.

- Urogenital—nephrectomy, nephroureterectomy, cystectomy.

- Liver cancers-segmental resection, lobectomy, transplantation.

- Brain cancers-craniectomy with resection.

Other surgery (ie, not cancer related)

- Hysterectomy with or without oophorectomy.

\section{Statistical analysis}

Analysis of HRT use after cancer diagnosis

Patients will be followed from 6 months after cancer diagnosis to cancer-specific mortality (censored on death from other causes or end of follow-up). A delay such as this is recommended to exclude deaths related to severe pathology to which HRT use is unlikely to have contributed. The length of the delay will be varied for certain cancers (such as melanoma, non-Hodgkin's lymphoma, bladder, colorectal and thyroid cancer) as they have better prognosis.

A dose-response analysis will be conducted based on DDD's, and number and duration of prescriptions. To avoid immortal time bias, HRT use will be modelled as a time varying covariate, that is, patients will only be considered users after a lag of 6 months from their first HRT prescription. Therefore, individuals will be considered users of 0-1 year from 6 months after their first prescription to 6 months after their 12th prescription (or 365th DDD) and $>1$ year users after this time (table 3A). Other elements of HRT prescription, namely dose, means of administration and whether administration is continuous or cyclical will be investigated through stratification of the sample.

Time-dependent Cox regression models will be used to calculate HRs, and 95\% CIs, for HRT use after cancer diagnosis adjusting for potential confounders including: age at diagnosis, BMI, year of diagnosis, alcohol and smoking status, ethnicity, deprivation index, stage, grade, cancer treatment, comorbidities, routine medications and prior hysterectomy/oophorectomy.

\section{Analysis of HRT use before cancer diagnosis}

Patients will be followed from diagnosis to cancer-specific mortality. HRT use will be identified in the 18 months prior to diagnosis, excluding the 6 months immediately prior to diagnosis (table 3B). Exclusion of HRT use in this period is intended to avoid bias arising from potentially short-term prescriptions issued in the lead up to cancer diagnosis that are unlikely to affect the outcome and may result in misclassification. ${ }^{52}$ Cox regression models will be used to calculate HRs and 95\% CIs for cancer-specific

Table 3 A-C: Categorisation of hormone replacement therapy (HRT) users for each proposed analysis

Label Definition

3A. HRT use after cancer diagnosis

Non-user No HRT prescription, or $<6$ months from first HRT prescription

0-1 year user $\quad 6$ months after first prescription until 6 months after 12th prescription or 6 months after 365th DDD

$>1$ year user Prescriptions beyond above time points

3B. HRT use before cancer diagnosis

Non-user $\quad$ No HRT prescription in the period from 18 months to 6 months before cancer diagnosis

User $\quad$ HRT prescription in the period from 18 months to 6 months before cancer diagnosis

3C. HRT use and CVD

$\begin{array}{ll}\text { Non-user } & \text { A woman without an HRT prescription } \\ \text { Current user } & \text { A woman with a valid HRT prescription } \\ \text { Past user } & \text { A woman whose HRT prescription has expired and who does not renew the prescription within } 30 \text { days }\end{array}$

CVD, cardiovascular disease; DDD, daily defined dose. 
death in HRT users compared with non-users. Adjusted Cox regression models will include: age at diagnosis, BMI, year of diagnosis, alcohol and smoking status, ethnicity, deprivation index, comorbidities, prior hysterectomy/ oophorectomy and routine medication use before diagnosis. Stage, grade and cancer treatments will initially be excluded from the models investigating HRT before diagnosis, as they could lie on the causal pathway. Subsequent analysis, however, will explore their potential role as confounders or effect mediators. Similar analyses will be conducted for secondary outcomes.

\section{Confounding factors for specific cancer sites}

Analyses will be stratified by cancer site, and some sites will be adjusted for additional covariates that have been shown to be associated with outcome at those sites. For instance, analysis of lung cancer will additionally contain histology (small-cell/non-small-cell) and beta-blocker use; colorectal will additionally contain site (colon, rectum or rectosigmoid colon), family history of colorectal cancer and inflammatory bowel disease; and oesophageal will contain histology (adenocarcinoma and squamous cell).

\section{Analysis of CVD}

In the secondary analysis of CVD, a start/stop time-varying covariate analysis will be conducted to investigate current HRT use, in which patients will become HRT users on the date of each HRT prescription, and remain HRT users until the end of their current prescription, at which point they will become past HRT users (table 3C) unless they initiate another HRT treatment within 30 days.

Cox regression models will be used to calculate HRs and 95\% CIs for CVD events in HRT users and nonusers. Adjustment will be made for: age at diagnosis, BMI, ethnicity, alcohol and smoking status, year of diagnosis, comorbidities and medications.

\section{Meta-analysis}

The HRs and SEs from these analyses will be pooled with identical analyses conducted on cohorts from Scotland and Wales. This two-stage analysis procedure will use random effects models to pool results across cohorts.

\section{Sensitivity analyses}

Confounding will primarily be addressed by entering a wide range of covariates into the Cox regression models. A number of additional sensitivity analyses will also be conducted to check for potential bias and subgroup effects including the following:

1. Analyses will be stratified into age categories of: 18 to $<40,40$ to $<55$ and $\geq 55$ years old. Women younger than 40 are more likely to have experience premature ovarian insufficiency whereas those 55 or over are likely to have experienced natural menopause.

2. An analysis of HRT after cancer diagnosis will be conducted using a new-user design, that is, restricting analyses to patients with cancer who did not use HRT before diagnosis.
3. A negative control analysis will be conducted to check for unmeasured confounding by repeating the main analysis with death from other causes as the outcome because HRT is not expected to influence death from other causes (excluding cancer and CVD).

4. It is possible that poor compliance may confound the analyses. To investigate this an analysis excluding individuals with only one prescription will be conducted, as patients continuing to be prescribed HRT are more likely to be adhering to their prescriptions.

5. A propensity score matched analysis will be conducted. First, logistic regression will be used to determine the propensity to be prescribed HRT. Matching will be implemented in Stata (Statacorp LLC, Texas, USA) to identify a HRT user group and a propensity score matched non-user group. Cox regression will then be used to determine the time to cancer-specific death in the two groups.

\section{Missing data}

Multiple imputation will be used to impute missing values for variables including BMI, smoking and alcohol status, stage and grade according to published guidelines. ${ }^{53}$ As recommended, cancer-specific death status and cumulative hazard will be included in imputation models as will all variables included in regression models. The number of imputed datasets will correspond to the proportion of missing data and results will be combined using Rubin's rules. ${ }^{54}$

\section{Limitations}

The completeness of stage data will be of importance to the analysis of HRT after diagnosis. Stage completeness is expected to be high for the majority of cancers we propose investigating including lung cancer $(\sim 90 \%)$; colorectal cancer $(\sim 90 \%)$ and malignant melanoma $(\sim 80 \%) .{ }^{55}$ For other sites and earlier years of diagnosis, however, stage is more likely to be missing, so it will be imputed by multiple imputation where necessary. Stage completeness is not expected to unduly influence the analysis of HRT before cancer diagnosis on survival and is arguably not appropriate, as it could lie on the causal pathway in these cases.

Smoking and BMI are well recorded in GP records but are not complete. Completeness for smoking is estimated to be approximately $95 \%$ in recent UK GP records and for BMI it is roughly $80 \%$. Multiple imputation will be used to impute missing values for these factors.

There are several potential sources of bias that arise from a likely difference in prescribing patterns of HRT for women with cancer. An allocation bias may arise because women with more severe cancer are less likely to be prescribed HRT and therefore more likely to be allocated to the unexposed group. Alternatively, there may be a general aversion to prescribing HRT in this population, so that only those women whose cancers have a high chance of remission are considered for HRT. We will seek to address this in several ways, first, these concerns would not affect prescription patterns prior to cancer 


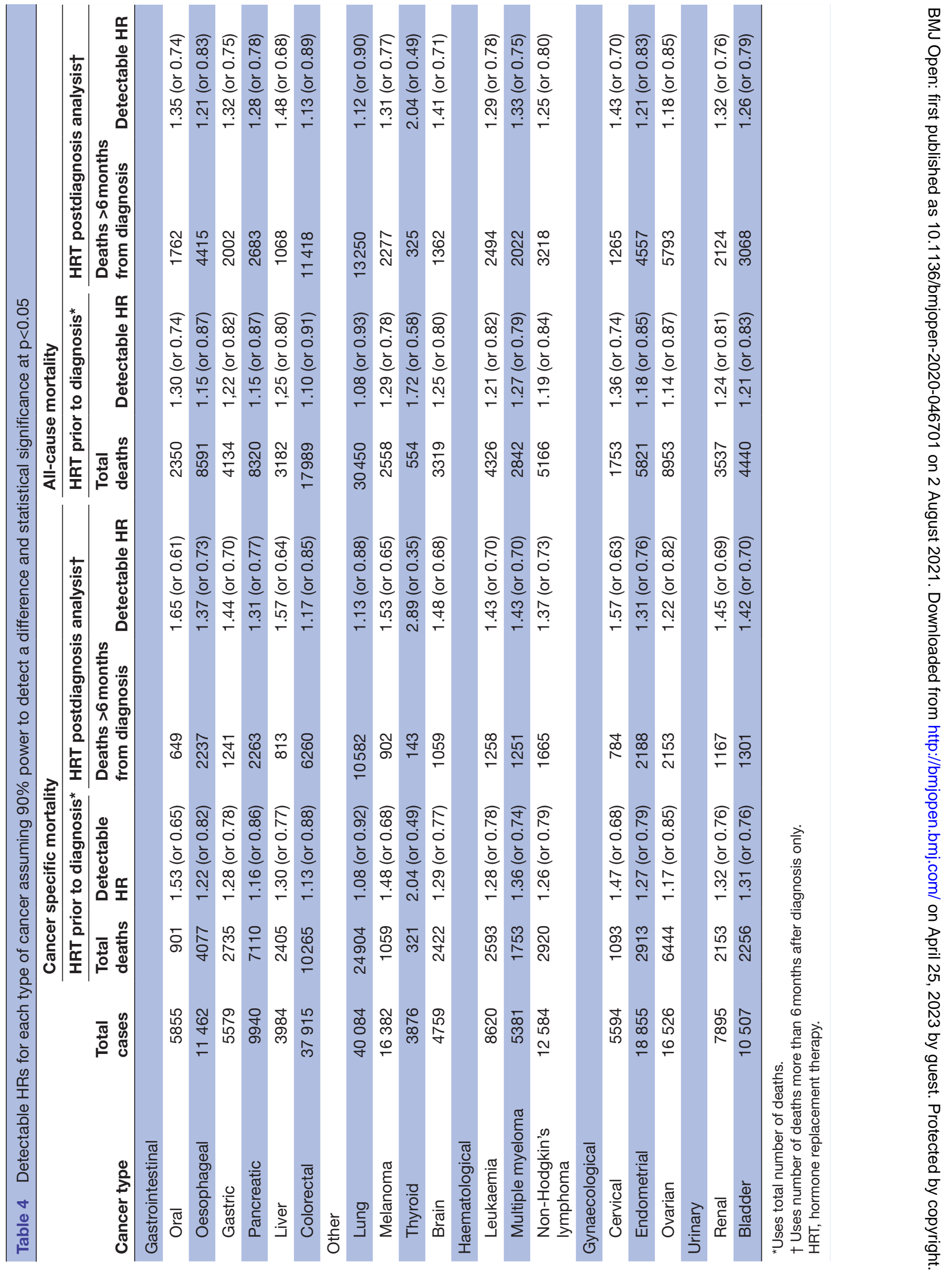


diagnosis, second, a 'new-user' sensitivity analysis will be conducted which excludes individuals with a history of HRT use prior to their cancer diagnosis. These analyses will provide a basis for assessing the potential impact of differing prescribing patterns and allocation bias.

\section{Sample size calculation}

Detectable HRs were calculated based on case numbers from the English study cohort (table 4). Statistical power to detect a difference (the beta value) was set at $90 \%$ and significance (the alpha value) at $5 \%$. We estimated that $7 \%$ of female patients with cancer would use HRT after diagnosis, consistent with published reports of roughly $5 \%$ HRT usage in a Swedish population-based colorectal cancer cohort after diagnosis, ${ }^{34}$ and $9 \%$ HRT usage in a Danish melanoma cohort after diagnosis. ${ }^{56}$ These calculations show that we would be able to detect HRs of 1.5 or greater with HRT use after diagnosis for most cancer sites.

\section{ETHICS AND DISSEMINATION}

Ethical approval for this project was obtained from the QResearch scientific committee (Ref: OX24, project title 'Use of hormone replacement therapy and survival from cancer'). Ethical approval for the QResearch database is obtained annually from East Midlands - Derby Research Ethics Committee (Ref: 18/EM/0400).

The findings of this study will be submitted for peerreviewed publication in an academic journal. In addition, the findings will be provided to Cancer Research UK for public dissemination, with the assistance of the Patient and Public Involvement (PPI) panel.

\section{PATIENT AND PUBLIC INVOLVEMENT}

The project will be supported throughout by a PPI panel, made up of women with experience of non-oestrogenic cancers. Members of the Northern Ireland Cancer Research Consumer Forum, patients with a cancer group, provided feedback on the project proposal before submission to Cancer Research United Kingdom (CRUK).

Another PPI panel of four women with a previous diagnosis of cancer was convened to inform the English component of this project (ie, the one presented in this protocol). They agreed the study was important and potentially valuable for female cancer survivors who experience menopausal symptoms. The panel suggested that both cancer-specific mortality and subsequent cancer diagnoses would be of interest to women in this demographic considering whether to use HRT. Future discussions will seek feedback on the relevance and resonance of findings and guide us on research communications and dissemination.

Contributors All authors were involved in the preparation of this manuscript. CRC conceived the study, and TAR, JB, AKC, WXM, PST, CRC and JH-C made substantial contributions to the study design. TAR, CC, $\mathrm{CRC}$ and $\mathrm{JH}-\mathrm{C}$ made substantial contributions to the acquisition and analysis of data. TAR drafted the original manuscript. JB, AKC, WXM, CC, PST, SD, CRC and JH-C provided critical revision of the manuscript for major intellectual content. All authors have approved the final version of this manuscript for publication and agree to be accountable for all aspects of the work in ensuring that questions related to the accuracy or integrity of any part of the work are appropriately investigated and resolved.

Funding This work was supported by Cancer Research UK [grant number: C37316/A29656]. JH-C has received grants from the National Institute for Health Research Biomedical Research Centre, 0xford, John Fell Oxford University Press Research Fund, Cancer Research UK (grant number C5255/A18085) through the Cancer Research UK Oxford Centre, and the Oxford Wellcome Institutional Strategic Support Fund (204826/Z/16/Z) during the conduct of the study. AKC is supported by a Clinical Research Training Fellowship from Cancer Research UK (DCS-CRUK-CRTF20-AC).

Competing interests $\mathrm{JH}-\mathrm{C}$ is an unpaid director of the Qresearch database (partnership between the University of Oxford and EMIS, commercial supplier of GP computer systems). She is shareholder and former director of ClinRisk Ltd outside the submitted work. PST reports consulting with AstraZeneca and Duke-NUS outside the submitted work.

Patient and public involvement Patients and/or the public were involved in the design, or conduct, or reporting, or dissemination plans of this research.

Patient consent for publication Not required.

Provenance and peer review Not commissioned; peer reviewed for ethical and funding approval prior to submission.

Open access This is an open access article distributed in accordance with the Creative Commons Attribution 4.0 Unported (CC BY 4.0) license, which permits others to copy, redistribute, remix, transform and build upon this work for any purpose, provided the original work is properly cited, a link to the licence is given, and indication of whether changes were made. See: https://creativecommons.org/ licenses/by/4.0/.

\section{ORCID iDs}

Tom Alan Ranger http://orcid.org/0000-0003-3091-2337

Ashley Kieran Clift http://orcid.org/0000-0002-0061-979X

Winnie Xue Mei http://orcid.org/0000-0002-6279-4884

Sharon Dixon http://orcid.org/0000-0002-7469-6093

Julia Hippisley-Cox http://orcid.org/0000-0002-2479-7283

\section{REFERENCES}

1 Hamoda H, Panay N, Arya R, et al. The British Menopause Society \& Women's Health Concern 2016 recommendations on hormone replacement therapy in menopausal women. Post Reprod Health 2016;22:165-83.

2 Goodman NF, Cobin RH, Ginzburg SB, et al. American association of clinical endocrinologists medical guidelines for clinical practice for the diagnosis and treatment of menopause: Executive summary of recommendations. Endocr Pract 2011;17:949-54.

3 Menon U, Burnell M, Sharma A, et al. Decline in use of hormone therapy among postmenopausal women in the United Kingdom. Menopause 2007;14:462-7.

4 Ameye L, Antoine C, Paesmans M, et al. Menopausal hormone therapy use in 17 European countries during the last decade. Maturitas 2014;79:287-91.

5 Beral V, Million Women Study Collaborators. Breast cancer and hormone-replacement therapy in the Million women study. Lancet 2003;362:419-27.

6 Cagnacci A, Venier M. The controversial history of hormone replacement therapy. Medicina 2019;55:602.

7 Rossouw JE, Anderson GL, Prentice RL, et al. Risks and benefits of estrogen plus progestin in healthy postmenopausal women: principal results from the women's health Initiative randomized controlled trial. JAMA 2002;288:321-33.

8 Marjoribanks J, Farquhar C, Roberts $\mathrm{H}$, et al. Long-term hormone therapy for perimenopausal and postmenopausal women. Cochrane Database Syst Rev 2017;1:CD004143.

9 Shen SS, Smith CL, Hsieh J-T, et al. Expression of estrogen receptors-alpha and -beta in bladder cancer cell lines and human bladder tumor tissue. Cancer 2006;106:2610-6.

10 Wang X, Chen Q, Huang X, et al. Effects of $17 \beta$-estradiol and tamoxifen on gastric cancer cell proliferation and apoptosis and ER$\alpha 36$ expression. Oncol Lett 2017;13:57-62.

11 Sukocheva OA, Wee C, Ansar A, et al. Effect of estrogen on growth and apoptosis in esophageal adenocarcinoma cells. Dis Esophagus 2013;26:628-35. 
12 Kanda N, Watanabe S. $17 \beta$-estradiol, Progesterone, and Dihydrotestosterone Suppress the Growth of Human Melanoma by Inhibiting Interleukin-8 Production. Journal of Investigative Dermatology 2001;117:274-83.

13 Hammoud Z, Tan B, Badve S, et al. Estrogen promotes tumor progression in a genetically defined mouse model of lung adenocarcinoma. Endocr Relat Cancer 2008;15:475-83.

$14 \mathrm{Ge} \mathrm{H}$, Yan Y, Tian F, et al. Prognostic value of estrogen receptor $\alpha$ and estrogen receptor $\beta$ in gastric cancer based on a metaanalysis and the cancer genome atlas (TCGA) datasets. Int J Surg 2018;53:24-31.

15 Cook MB, McGlynn KA, Devesa SS, et al. Sex disparities in cancer mortality and survival. Cancer Epidemiol Biomarkers Prev 2011;20:1629-37.

16 Radkiewicz C, Johansson ALV, Dickman PW, et al. Sex differences in cancer risk and survival: a Swedish cohort study. Eur J Cancer 2017;84:130-40.

$17 \mathrm{Kim} \mathrm{HW}$, Kim J-H, Lim BJ, et al. Sex disparity in gastric cancer: female sex is a poor prognostic factor for advanced gastric cancer. Ann Surg Oncol 2016;23:4344-51.

18 McGlynn KA, Hagberg K, Chen J, et al. Menopausal hormone therapy use and risk of primary liver cancer in the clinical practice research Datalink. Int J Cancer 2016;138:2146-53.

19 Hassan MM, Botrus G, Abdel-Wahab R, et al. Estrogen replacement reduces risk and increases survival times of women with hepatocellular carcinoma. Clin Gastroenterol Hepatol 2017;15:1791-9.

20 Simin J, Tamimi R, Lagergren J, et al. Menopausal hormone therapy and cancer risk: an overestimated risk? Eur J Cancer 2017;84:60-8.

21 Grodstein F, Newcomb PA, Stampfer MJ. Postmenopausal hormone therapy and the risk of colorectal cancer: a review and meta-analysis. Am J Med 1999;106:574-82.

22 Mørch LS, Lidegaard Øjvind, Keiding N, et al. The influence of hormone therapies on colon and rectal cancer. Eur J Epidemiol 2016;31:481-9.

23 Lope V, Fernández de Larrea N, Pérez-Gómez B, et al. Menstrual and reproductive factors and risk of gastric and colorectal cancer in Spain. PLoS One 2016;11:e0164620.

24 Benson VS, Kirichek O, Beral V, et al. Menopausal hormone therapy and risk of central nervous system tumours: a UK-based nested case-control study. Int J Epidemiol 2015;44:i52.

25 Jin C, Lang B. Hormone replacement therapy and lung cancer risk in women: a meta-analysis of cohort studies: hormone replacement therapy and lung cancer risk. Medicine 2019;98:e17532-e32.

26 Bae J-M, Kim EH. Hormonal replacement therapy and the risk of lung cancer in women: an adaptive meta-analysis of cohort studies. $J$ Prev Med Public Health 2015;48:280-6.

27 Kane EV, Bernstein L, Bracci PM, et al. Postmenopausal hormone therapy and non-Hodgkin lymphoma: a pooled analysis of InterLymph case-control studies. Ann Oncol 2013:24:433-41.

28 Costas L, Lujan-Barroso L, Benavente Y, et al. Reproductive factors, exogenous hormone use, and risk of B-cell non-Hodgkin lymphoma in a cohort of women from the European prospective investigation into cancer and nutrition. Am J Epidemiol 2019;188:274-81.

29 Morton LM, Wang SS, Richesson DA, et al. Reproductive factors, exogenous hormone use and risk of lymphoid neoplasms among women in the National Institutes of Health-AARP diet and health study cohort. Int J Cancer 2009;124:2737-43.

30 Daugherty SE, Lacey JV, Pfeiffer RM, et al. Reproductive factors and menopausal hormone therapy and bladder cancer risk in the $\mathrm{NIH}$ AARP diet and health study. Int J Cancer 2013;133:462-72.

31 Deli T, Orosz M, Jakab A. Hormone Replacement Therapy in Cancer Survivors - Review of the Literature. Pathol Oncol Res 2020;26:63-78.

32 Webber L, Anderson RA, Davies M, et al. HRT for women with premature ovarian insufficiency: a comprehensive review. Hum Reprod Open 2017;2017:hox007.

33 Edey KA, Rundle S, Hickey M. Hormone replacement therapy for women previously treated for endometrial cancer. Cochrane Database Syst Rev 2018;5:CD008830.
$34 \mathrm{Ji}$ J, Sundquist J, Sundquist K. Use of hormone replacement therapy improves the prognosis in patients with colorectal cancer: a population-based study in Sweden. Int $J$ Cancer 2018;142:2003-10.

35 Chan JA, Meyerhardt JA, Chan AT, et al. Hormone replacement therapy and survival after colorectal cancer diagnosis. $J$ Clin Oncol 2006;24:5680-6.

36 Jang $\mathrm{Y}-\mathrm{C}$, Huang $\mathrm{H}-\mathrm{L}$, Leung CY. Association of hormone replacement therapy with mortality in colorectal cancer survivor: a systematic review and meta-analysis. BMC Cancer 2019;19:1199.

37 MacKie RM, Bray CA. Hormone replacement therapy after surgery for stage 1 or 2 cutaneous melanoma. Br J Cancer 2004;90:770-2.

38 Krul IM, Opstal-van Winden AWJ, Aleman BMP, et al. Breast cancer risk after radiation therapy for Hodgkin lymphoma: influence of gonadal hormone exposure. Int J Radiat Oncol Biol Phys 2017;99:843-53.

39 Yang X, Wang C, He X, et al. Hormone therapy for premature ovarian insufficiency patients with malignant hematologic diseases. Climacteric 2017;20:268-73.

40 Ganti AK. Another nail in the coffin for hormone-replacement therapy? Lancet 2009;374:1217-8.

41 Biglia N, Gadducci A, Ponzone R, et al. Hormone replacement therapy in cancer survivors. Maturitas 2004;48:333-46.

42 Cobin RH, Goodman NF, Committee A, AACE Reproductive Endocrinology Scientific Committee. American association of clinical endocrinologists and American College of endocrinology position statement on MENOPAUSE-2017 update. Endocr Pract 2017;23:869-81.

43 National Institute for Health and Care Excellence. Menopause: diagnosis and management, 2019.

44 Welton AJ, Vickers MR, Kim J, et al. Health related quality of life after combined hormone replacement therapy: randomised controlled trial. BMJ 2008;337:a1190.

45 Oliver-Williams C, Glisic M, Shahzad S, et al. The route of administration, timing, duration and dose of postmenopausal hormone therapy and cardiovascular outcomes in women: a systematic review. Hum Reprod Update 2019;25:257-71.

46 Kontopantelis E, Stevens RJ, Helms PJ, et al. Spatial distribution of clinical computer systems in primary care in England in 2016 and implications for primary care electronic medical record databases: a cross-sectional population study. BMJ Open 2018;8:e020738.

47 Hippisley-Cox J, Stables D, Pringle M. QRESEARCH: a new general practice database for research. Inform Prim Care 2004;12:49-50.

48 British Medical Association Joint Formulary Committee Pharmaceutical Society (Great Britain). British National formulary: pharmaceutical PR, 2003.

49 Vinogradova Y, Coupland C, Hippisley-Cox J. Use of hormone replacement therapy and risk of venous thromboembolism: nested case-control studies using the QResearch and CPRD databases. BMJ 2019;364:k4810.

50 Arık A, Dodd E, Streftaris G. Cancer morbidity trends and regional differences in England-A Bayesian analysis. PLoS One 2020;15:e0232844

51 Public Health England. Linking treatment tables - chemotherapy, tumour resections and radiotherapy. 58. 4.4 ed. Cancer Research UK - Public Health England, 2018.

52 Suissa S, Azoulay L. Metformin and the risk of cancer: time-related biases in observational studies. Diabetes Care 2012;35:2665-73.

53 White IR, Royston P, Wood AM. Multiple imputation using chained equations: issues and guidance for practice. Stat Med 2011;30:377-99.

54 Rubin DB. Multiple imputation for nonresponse in surveys. John Wiley \& Sons, 2004.

55 Registries UKalAoC. UKIACR: performance indicators 2018 report, 2018.

56 Hicks BM, Kristensen KB, Pedersen SA, et al. Hormone replacement therapy and the risk of melanoma in post-menopausal women. Hum Reprod 2019;34:2418-29. 